\title{
Allantoin improves histopathological evaluations in a rat model of gastritis
}

\author{
M Eslami-farsani ${ }^{1}$, A Moslehi ${ }^{2}$, A Hatami-shahmir ${ }^{3}$ \\ ${ }^{1}$ School of Medicine, Qom University of Medical Sciences, Qom, Iran \\ ${ }^{2}$ Cellular and Molecular Research Center, Qom University of Medical Sciences, Qom, Iran \\ ${ }^{3}$ Student Research Committee, Qom University of Medical Sciences, Qom, Iran
}

Received: February 4, 2018

Accepted: October 30, 2018

\begin{abstract}
Purpose: Gastritis is found to be one of the most common gastrointestinal diseases worldwide. However, current therapeutic agents cause side effects, interaction, and recurrence. Allantoin has anti-inflammatory and wound healing properties. In this study, the therapeutic effect of allantoin has been assessed on the histopathological indices and gastric mucosal barrier of male rats. Methods: Male rats were equally divided into control, ethanol-induced gastritis, and allantoin groups. The therapeutic groups consisted of gastritis plus $12.5 \mathrm{mg} / \mathrm{kg}$ allantoin, gastritis plus $25 \mathrm{mg} / \mathrm{kg}$ allantoin, and gastritis plus $50 \mathrm{mg} / \mathrm{kg}$ allantoin groups. After 5 days of allantoin administration, the rats were sacrificed and a part of their gastric tissue was maintained at $-70{ }^{\circ} \mathrm{C}$ for prostaglandin E2 (PGE2) and non-protein sulfhydryl (NP-SH) measurements. Another part was stained with hematoxylin and eosin and Masson's trichrome. Results: We found that Allantoin increased parietal and mucosal cell counts and mucosal thickness after gastritis induction. In addition, the number of leukocytes and vessels decreased in both of the mucosal and the submucosal layers. Allatoin improved gastric ulcer in all treatment groups. Gastric levels of PGE2 and NP-SH increased after allantoin treatment. Conclusion: This study indicated that allantoin had a considerable effect on gastritis treatment, which seems to result from the reinforcement of gastric mucosal barrier.
\end{abstract}

Keywords: allantoin, gastritis, ethanol, prostaglandin E2, stomach

\section{Introduction}

Gastric ulcer disease is identified by inflammation, ulcer, and cell loss in the epithelial layer of the stomach, which can develop to the gastric perforation or even gastric neoplasia $(2,10)$. In addition, gastric ulcer is one of the most prevalent gastrointestinal disorders throughout the world (2). It has been demonstrated that an imbalance between the protective and risk factors leads to gastritis (20). The risk factors for gastritis include smoking, stress, infection, frequent use of non-steroidal anti-inflammatory drugs, and excessive consumption of alcohol (10, 15, 16). Nowadays, the classic treatment for this disease includes proton pump inhibitors, $\mathrm{H} 2$ receptor blockers, and anti-acids. However, some of these drugs have shown a lot of side effects, interaction, and recurrence $(15,19)$. Therefore, many researchers attempt to find new drugs or approaches for gastritis treatment. Herbal medications are one of the most attractive compounds in this context.

Allantoin is one of the principal compounds in many plants, such as yam, Nelumbo nucifera rhizome, sugar beet, and leguminous and is a natural, safe, and non-toxic

\footnotetext{
Corresponding author: Azam Moslehi

Cellular and Molecular Research Center, Qom University of Medical Sciences

Pardis Complex, Alghadir Bolvar, Qom 37185, Iran

Phone/Fax: +98 253783 2470; E-mail: moslehi2000@gmail.com
} 
compound $(4,6)$. The wound healing and tissue regeneration effects of allantoin have already been well known $(3,14)$. It has also been reported that allantoin decreases IL-4, IL-5, Ig-E levels, and the number of leukocyte cells in the ovalbumin-induced lung inflammation (11). Florentino et al. (8) revealed that allantoin has anti-nociceptive and anti-inflammatory effects on the formalin-induced nociception test. Moreover, it has been shown that allantoin activates imidazoline I1-receptor (I1R) in animal and cell line studies $(5,22)$. Recent studies have shown that allantoin affects metabolic functions. For example, Chung et al. (5) have stated that allantoin alleviates obesity and hyperlipidemia via I1R activation in mice. In another experiment, allantoin improved cognitive function and neurogenesis in the mice hippocampus (1). Interestingly, da Silva et al. (7) have recently reported the gastroprotective effect of allantoin on gastric ulcer in female mice. Based on these observations, we designed experiments to study the treatment effect of allantoin on ethanol-induced gastritis in male rats.

\section{Material and Methods}

\section{Reagents}

Allantoin was purchased from Sigma Aldrich Chemical Co. (Lot. MKBB4594V; Sigma Aldrich, Chemie GmbH, Steinheim,Germany) and was dissolved in saline.

\section{Experimental procedures}

In this study, 36 male Wistar rats (obtained from Academic Center for Education, Culture \& Research, Qom, Iran) weighing 200-250 g were used. The rats were housed in a temperaturecontrolled room with 12-h light-dark cycles and free access to standard laboratory chow and water. All the procedures followed were in accordance with the Guidelines for Animal Care and Use at the Qom University of Medical Sciences (IR.MUQ.REC.1394.102).

The rats were randomly divided into six equal groups $(N=6)$ : the control group, which received $1 \mathrm{ml}$ per oral (p.o) saline by gavage; gastritis group, in which the fasted rats received $100 \%$ ethanol ( $1 \mathrm{ml} \mathrm{p.o} \mathrm{by} \mathrm{gavage,} \mathrm{single} \mathrm{dose)} \mathrm{to} \mathrm{induce} \mathrm{gastritis} \mathrm{(2);} \mathrm{and} \mathrm{allantoin} \mathrm{group,}$ which received $50 \mathrm{mg} / \mathrm{kg}$ allantoin $(1 \mathrm{ml}$ p.o by gavage) to find out possible toxic effects. In the next groups, rats received allantoin after gastritis induction in different doses. Gastritis plus 12.5 allantoin group (G-A-12.5) received $12.5 \mathrm{mg} / \mathrm{kg}$ allantoin [intragavage (i.g.)]. Gastritis plus 25 allantoin group (G-A-25) received $25 \mathrm{mg} / \mathrm{kg}$ allantoin (i.g.) (11) and gastritis plus 50 allantoin group (G-A-50) received $50 \mathrm{mg} / \mathrm{kg}$ allantoin (i.g.) (11). Allantoin administration was performed for 5 days consecutively (9). On the 6th day, the rats were anesthetized by an intraperitoneal (i.p.) injection of $50 \mathrm{mg} / \mathrm{kg}$ of sodium thiopental and sacrificed (17). The abdomen was excised through midline incision and the stomach was removed. A part of the stomach was dissected and fixed in $10 \%$ buffered formaldehyde solution. Paraffin blocks were then prepared for histopathological findings. Another part of the stomach was dissected and kept at $-70{ }^{\circ} \mathrm{C}$ for evaluation of PGE2 and non-protein sulfhydryl (NP-SH) levels.

\section{Histological study}

After a minimum of $24 \mathrm{~h}$ from fixation, the tissues were dehydrated by putting them in ascending concentrations of ethanol solutions (30\%, 50\%, 70\%, 90\%, and 100\%), then washed with xylene and embedded in paraffin wax. Afterward, the samples were sectioned with a microtome and stained with hematoxylin and Eosin (H\&E) and Masson's trichrome stain, and mounted with Canada balsam. All sections were studied by Olympus light microscope (CX23 LED Microscope, Japan). Photomicrographs of the stomach tissue were 
taken in $4 \times, 10 \times$, and $40 \times$ magnification for observation and demonstration of histopathologic lesions. Histological features assayed included mucosal thickness and ulcer area and the number of leukocytes, parietal cells, mucosal cells and vessels. For this purpose, five sections of each tissue sample were observed and in each section, four fields were evaluated by ImageJ software (National Institutes of Health, ImageJ 1.49f, USA).

\section{Tissue PGE2 measurement}

Weighed samples of tissues (approximately $0.5 \mathrm{~g}$ ) were homogenized in 2-ml microfuge tubes by an electrical homogenizer (IKA-3420000, Germany). The supernatants were then assayed for PGE2 levels using an immunometric enzyme immunoassay (EIA) kit according to the manufacturer's instruction (ADI-900-001).

\section{NP-SH measurement}

The content of gastric NP-SH was measured from supernatant obtained from 100-mg gastric tissue in $1 \mathrm{ml}$ of $0.02 \mathrm{M}$ EDTA, distilled water, and trichloroacetic acid. The supernatants were then mixed with Tris buffer and 5,5-ditiobis (2-nitrobenzoic acid), according to Shin et al.'s method (19). The absorbance was measured at $412 \mathrm{~nm}$ and reported as $\mu \mathrm{g} / \mathrm{g}$ of the gastric tissue using the standard curve.

\section{Statistical analysis}

Data were expressed as mean \pm standard error of the mean. Statistical analysis was performed by one-way analysis of variance and Tukey's post hoc test using SPSS for Windows version 11.5 (IBM SPSS version 11.5; USA). $p<0.05$ was considered to be statistically significant.

\section{Results}

\section{Effect of allantoin on the mucosal thickness}

The mucosal layer thickness was measured in millimeter ( $\mathrm{mm}$ ) from the mucosal muscle to the apex of the epithelial cells at a magnification of $40 \times$ in four fields from the photomicrograph by software. For each sample, five sections were examined and their mean was considered as the average thickness of the mucus layer. As shown in Figs 1a and 2, the mucosal thickness significantly decreased in the gastritis group compared to the control group $(14.93 \pm 1.74$ vs. $27.85 \pm 1.46, p<0.01)$. However, allantoin administration increased

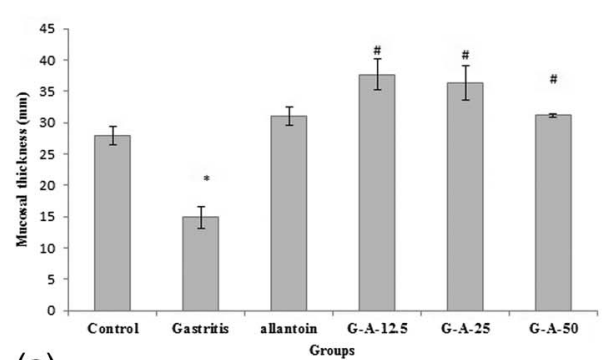

(a)

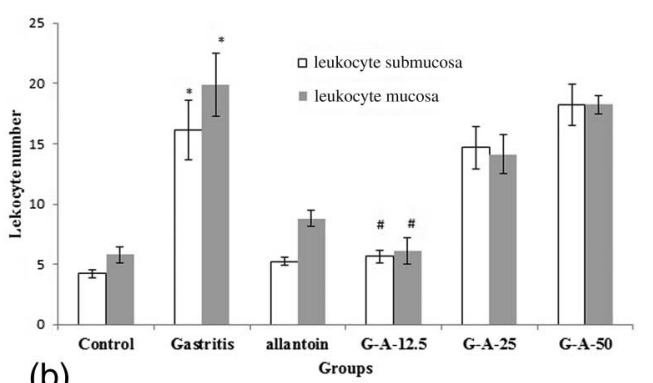

(b)

Fig. 1. (a) Mucosal layer thickness of the gastric tissue in different groups. Mean $\pm \mathrm{SEM}, N=6,{ }^{*} p<0.01$ compared to control. ${ }^{\#} p<0.001$ compared with gastritis group. (b) Leukocyte numbers of mucosal and submucosal layers in different groups. Mean $\pm \mathrm{SEM}, N=6,{ }^{*} p<0.001$ compared to control. ${ }^{*} p<0.001$ compared to the gastritis group 


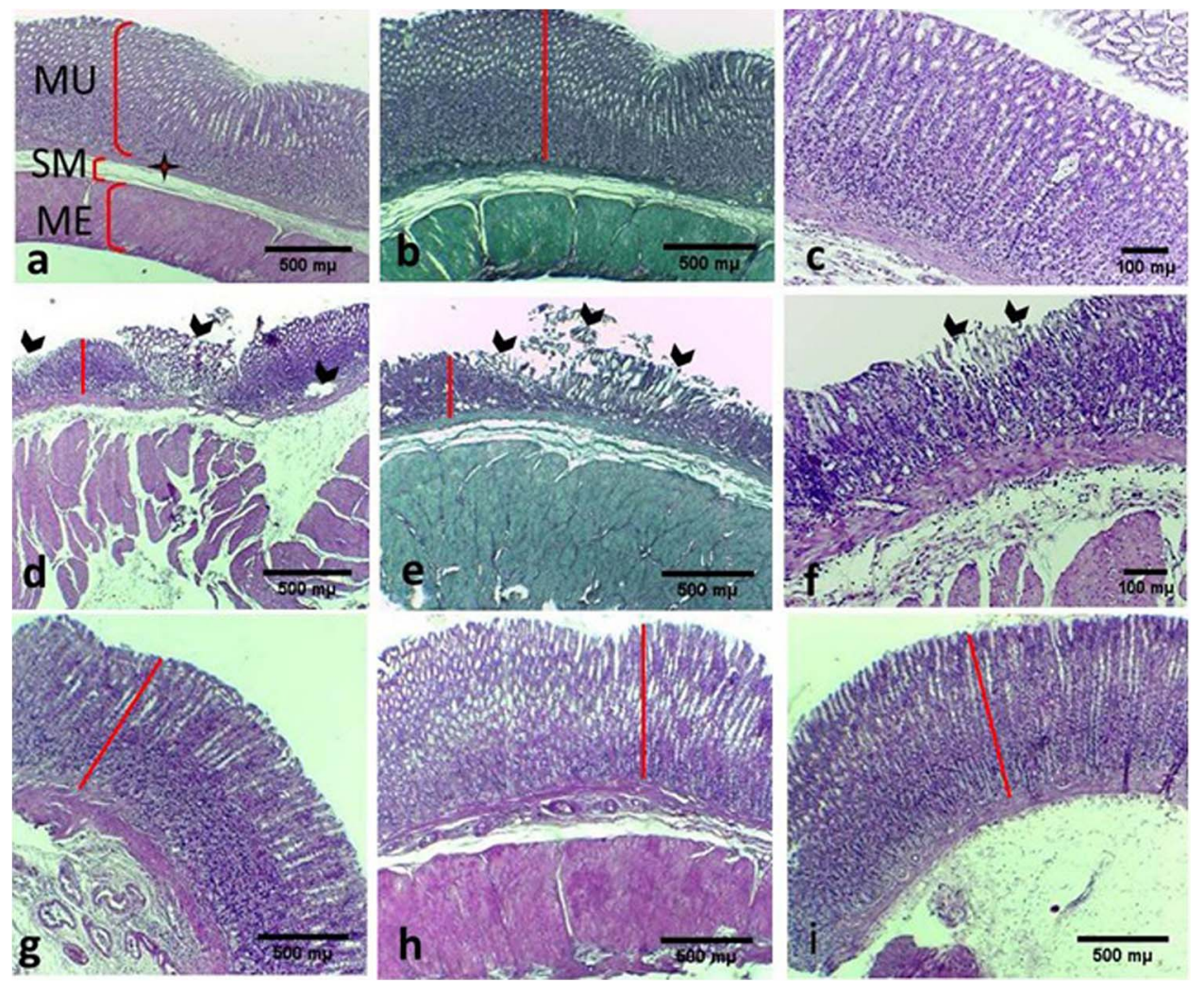

Fig. 2. Histopathological findings of the gastric tissue in different groups. (a-c) The control group: showing normal mucosal layer of the gastric tissue. (d-f) The gastritis group: showing detachment and loss of mucosal layer (head of arrow). (g-i) Treatment groups $(12.5,25,50 \mathrm{mg}$ allantoin, respectively): showing improvement of ulcers and increase of mucosal layers (b, e: Masson's trichrome, 4×), (a, c, d, f-i: H\&E, 4×). MU: mucosal layer;

SM: submucosal layer; ME: muscular extern

mucosal thickness in all treatment groups (G-A-12.5, allantoin, G-A-25 allantoin, and G-A-50 allantoin groups; $37.66 \pm 2.4,36.4 \pm 2.73,31.16 \pm 0.27$ vs. $14.93 \pm 1.74$, $p<0.001$, respectively).

\section{Effect of allantoin on the number of leukocytes}

The obtained findings revealed that the leukocyte numbers in both of the mucosal and the submucosal layers increased in the gastritis group compared to the control group (19.88 \pm 2.6 vs. $5.77 \pm 0.66, p<0.001$ and $16.11 \pm 2.46$ vs. $4.22 \pm 0.32, p<0.001$, respectively). However, the leukocyte numbers decreased in the G-A-12.5 allantoin group compared to the gastritis group in both layers $(5.66 \pm 0.52$ vs. $19.88 \pm 2.6$ and $6.11 \pm 0.07$ vs. $16.11 \pm 2.46$, $p<0.001$, respectively), whereas in other groups, no significant decreases were observed (Fig. 1b).

\section{Effect of allantoin on the ulcer areas}

For the ulcer area measurement, the length and thickness of the ulcer in $\mathrm{mm}^{2}$ were measured at a magnification of $40 \times$ with the software and the area of the gastric ulcer was obtained in 
each section. Five sections were examined for each sample. Our results showed that ulcer areas significantly increased in the gastritis group compared to the control group $\left(56.52 \pm 10.6\right.$ vs. $\left.0 \mathrm{~mm}^{2}, p<0.001\right)$. However, allantoin treatment significantly lowered ulcer areas in the G-A-12.5 allantoin, G-A-25 allantoin, and G-A-50 allantoin groups compared to the control group $(24.81 \pm 7.48,10.6 \pm 5.35$, and $10.24 \pm 2.65$ vs. $56.52 \pm 10.6, p<0.001$, respectively; Fig. 3c).

Effect of allantoin on the number of the parietal and mucosal cells

For counting the cells, the average values of the cells at four microscopic fields in each section were considered by the image $J$ software at a magnification of $400 \times$ (Fig. 4). The average number of cells in five stomach sections from each sample was considered as the number of cells in that specimen.

Histological evaluations revealed that ethanol administration significantly decreased the number of parietal and mucosal cells compared to the control group $(1.55 \pm 0.37 \mathrm{vs}$. $13.66 \pm 0.78, p<0.001$ and $1.66 \pm 0.55$ vs. $6.88 \pm 0.56, p<0.001$ respectively). Meanwhile, the number of parietal cells increased in the G-A-12.5 allantoin, G-A-25 allantoin, and G-A-50 allantoin groups compared to the gastritis group $(14.22 \pm 1.1,9.66 \pm 1.17$, and $9.44 \pm 0.74$ vs. $1.55 \pm 0.37, p<0.001$, respectively). Similarly, allantoin administration increased the mucosal cells in the G-A-12.5 allantoin, G-A-25 allantoin, and G-A-50 allantoin groups compared to the gastritis group $(10.11 \pm 1.79,9.11 \pm 0.71$, and $6.8 \pm 0.59$ vs. $1.66 \pm 0.55, p<0.001$, respectively; Figs $3 a$ and 5).
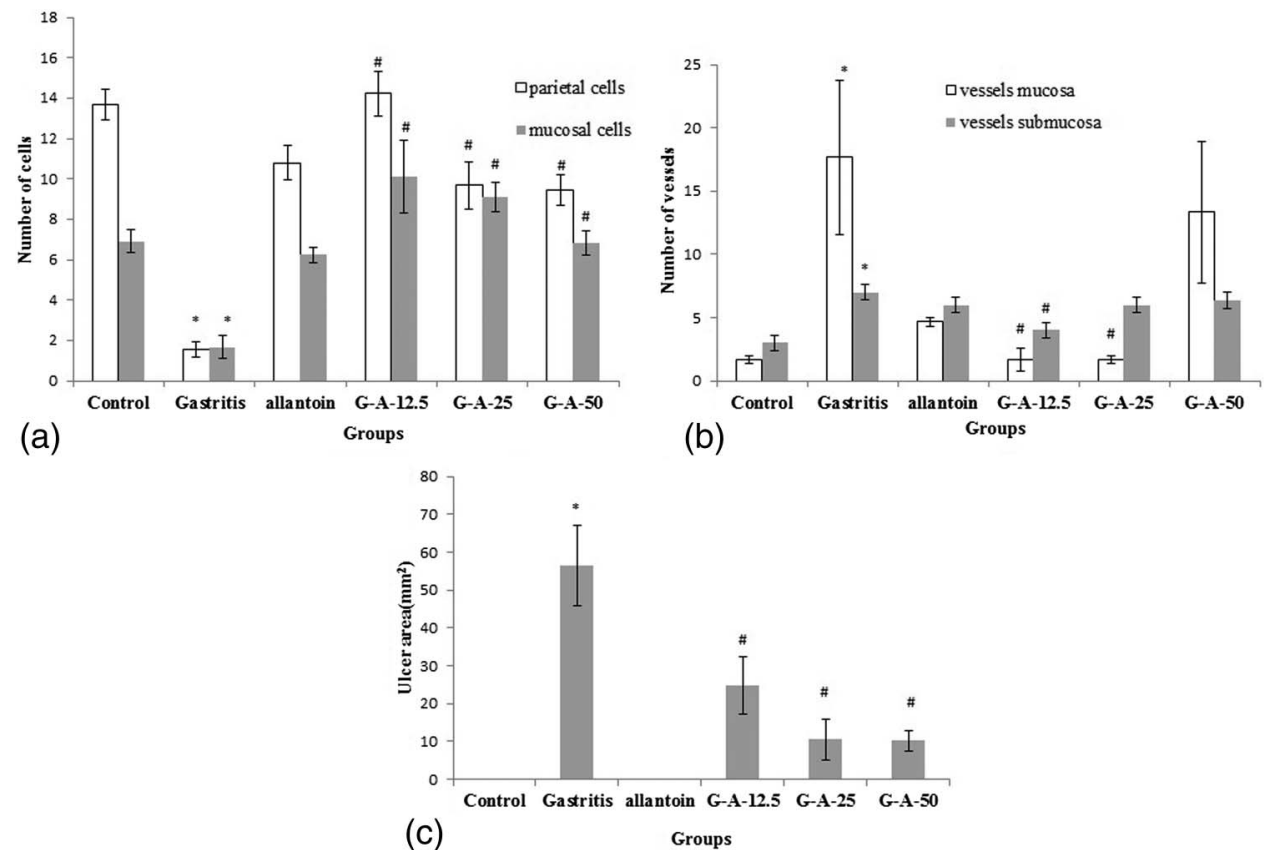

Fig. 3. (a) Number of cells in different groups. Mean \pm SEM, $N=6,{ }^{*} p<0.001$ compared to the control group. ${ }^{\#} p<0.001$ compared to the gastritis group. (b) Number of vessels of mucosal and submucosal layers in different groups. Mean \pm SEM, $N=6,{ }^{*} p<0.05$ compared to control. ${ }^{*} p<0.05$ compared to the gastritis group. (c) Ulcer areas of the gastric tissue in different groups. Mean $\pm \mathrm{SEM}, N=6,{ }^{*} p<0.001$ compared to control. ${ }^{\#} p<0.001$ compared to the gastritis group 

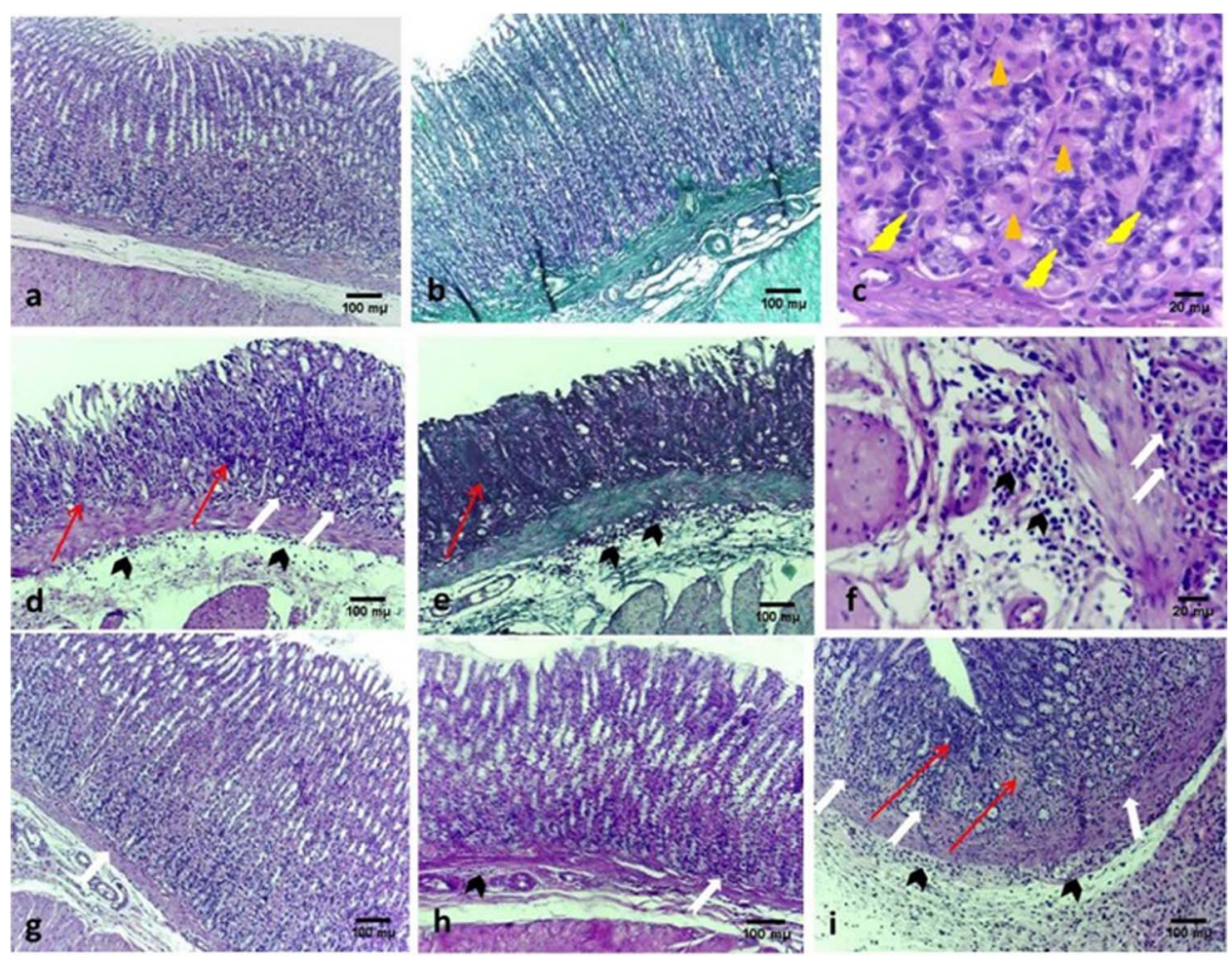

Fig. 4. Histopathological findings of the inflammatory cells in the mucosal (white arrow) and submucosal layers (head of black arrow) of different groups. Parietal cells (triangle), chief cells (wavy arrow). (a-c) The control group.

$(\mathrm{d}-\mathrm{f})$ The gastritis group: showing granulated tissue and fibrosis (thin arrow) and inflammatory cells. (g-i) G-A-12.5, G-A-25, G-A-50 groups, respectively; less inflammation in G-A-12.5 group (b, e: Masson's trichrome, 10×; a, c, d, f-i: H\&E, 4×; c, f: H\&E, 40×)

Effect of allantoin on the number of vessels

For counting lamina propria and submucosa vessels, similar to the cells counting, $100 \times$ magnification was used. As noted in Fig. 3b, gastritis markedly increased the number of vessels in the mucosal layer compared to the control group (17.66 \pm 6.06 vs. $1.66 \pm 0.33, p=0.01)$. However, the number of vessels significantly decreased in the G-A-12.5 allantoin and G-A-25 allantoin groups compared to the gastritis group $(1.66 \pm 0.88$ and $1.66 \pm 0.33$ vs. $17.66 \pm 6.06, p=0.01)$. However, the vessel numbers increased in the G-A-50 allantoin group.

Our findings also showed a significant increase in the gastritis group compared to the control group in the vessel number of the submucosal layer ( $7 \pm 0.57$ vs. $3 \pm 0.57, p=0.004$ ), but allantoin administration significantly decreased it only in the G-A-12.5 allantoin group compared to the gastritis group ( $4 \pm 0.57$ vs. $7 \pm 0.57, p=0.03)$.

\section{Effect of allantoin on PGE2 levels}

This study also revealed that gastric PGE2 levels significantly decreased in the gastritis group compared to the control group $(666.32 \pm 56.46$ vs. $1,533.25 \pm 16.41, p<0.001)$. However, PGE2 levels showed a significant increase in the treatment groups (G-A-12.5, 


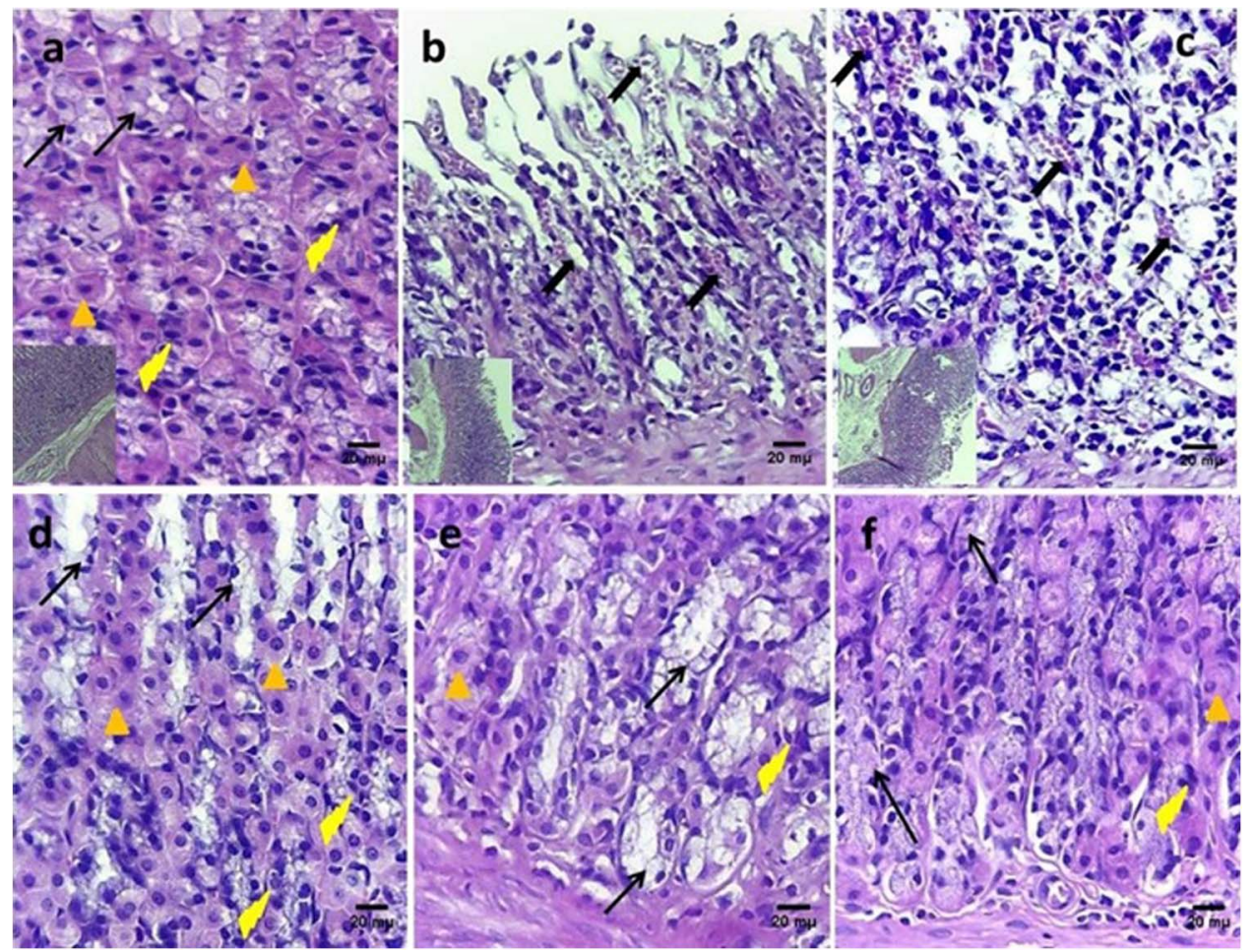

Fig. 5. Histopathological findings of the gastric tissues in different groups. Parietal cells (triangle), chief cells (wavy arrow), mucosal cells (thin arrow), and blood infiltration in submucosal layer (thick arrow). (a) The control group. (b, c) the gastritis group: showing the mess of the tissue and loss of gland and cell numbers. (d-f) G-A-12.5, G-A-25, G-A-50 groups; increase of glands and cell numbers, respectively (a-f: H\&E, 40×)
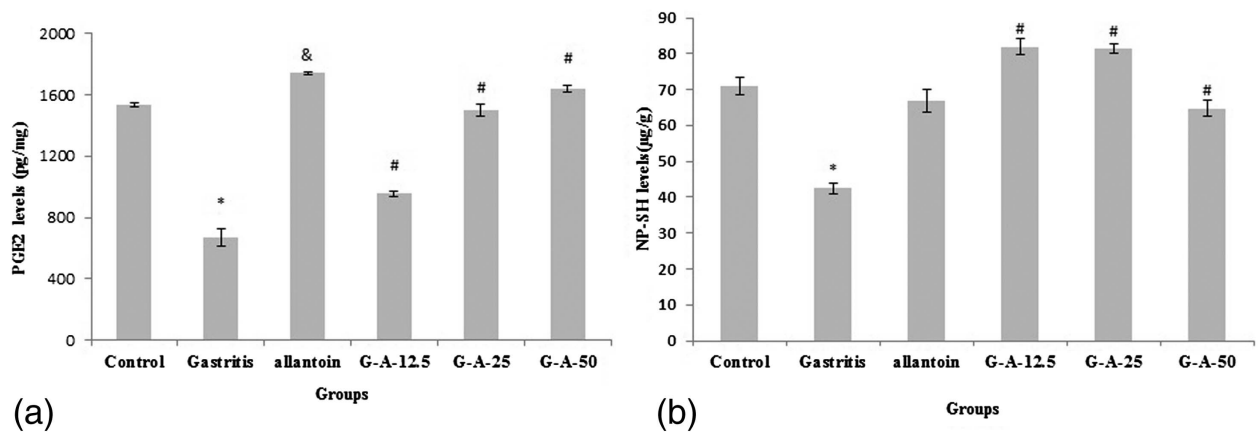

Fig. 6. (a) PGE2 levels of the gastric tissue in different groups. Mean $\pm \mathrm{SEM}, N=6,{ }^{*} p<0.001$ compared to control. ${ }^{\#} p<0.001$ compared to the gastritis group. (b) NP-SH levels of the gastric tissue in different groups. Mean \pm SEM, $N=6,{ }^{*} p<0.001$ compared to control. ${ }^{\#} p<0.001$ compared to the gastritis group

allantoin, G-A-25 allantoin, and G-A-50 allantoin groups) compared to the gastritis group $(956.12 \pm 17.83,1,499.62 \pm 42.25$, and $1,638.95 \pm 21.31$ vs. $666.32 \pm 56.46 \mathrm{pg} / \mathrm{mg}$, $p<0.001$, respectively; Fig. 6a). 
Effects of allantoin on the gastric NP-SH levels

Our results showed that gastric contents of mucosal NP-SH significantly decreased in the gastritis group compared to the control group $(42.46 \pm 1.48$ vs. $71.0275 \pm 2.34, p<0.001)$. However, allantoin treatment in the G-A-12.5 allantoin, G-A-25 allantoin, and G-A-50 allantoin groups significantly increased NP-SH levels compared to the gastritis group $(81.8875 \pm 2.14,81.3125 \pm 1.26$, and $64.745 \pm 2.15$ vs. $42.46 \pm 1.48, p<0.001$, respectively; Fig. 6b).

\section{Discussion}

The beneficial effects of allantoin on inflammation, oxidative activities, and wound healing have been well known $(8,9)$. In this study, we showed that allantoin improved gastritis, mucosal thickness, and cell numbers after ethanol-induced gastritis, decreased leukocyte, and vessel numbers and increased the PGE2 and NP-SH levels in the gastric tissue of male rats.

Long-term alcohol consumption is considered to be a risk factor for peptic ulcer, and ethanol administration experimentally induces gastritis, mucosal layer hyperemia, mucosal cell loss, and leukocyte infiltration in rats $(3,14,18)$. Our results showed that ethanol decreased the mucosal layer thickness, parietal, and mucosal cell numbers and NP-SH levels, whereas allantoin treatment increased mucosal thickness, parietal, and mucosal cell counts and NP-SH levels. Gastric mucosal barrier and bicarbonate rich mucus are the first defense line against ulceration and it seems that allantoin treatment could increase mucosal cell number, mucus secretion, and mucosal thickness and cause gastritis improvement. NP-SHs help to maintain mucosal integrity and free radical scavenging. Increased NP-SH levels after allantoin treatment probably provide mucosal thickness increment and gastritis healing. These findings are also consistent with several reports, which demonstrated that silymarin and extract of glutinous rice increased NP-SH levels and mucus contents and had gastroprotective effect on the gastric ulcer $(19,20)$. The increased number of leukocyte cells is considered to be a sign of inflammation in the tissue. Our findings revealed that in both mucosal and submucosal layers, leukocyte cells increased in the gastritis group and allantoin administration led to decrement of the leukocyte cell number. Vessel numbers also increased after ethanol use, whereas allantoin decreased the number of vessels. It seems that increasing leukocyte and vessel numbers result from inflammation and hyperemia induced by gastritis in the stomach (12). In this context, it has been reported that allantoin decreased IL4, IL5, and inflammatory cell infiltration in asthma-induced rats (11). Furthermore, da Silva et al. (7) have recently shown that allantoin decreases TNF $\alpha$ and IL1 $\beta$ in gastritis induced in female mice. Our results are in agreement with these documents and demonstrate anti-inflammatory effects of allantoin in the ethanolinduced gastritis in male rats. However, in this study, leukocyte cell and vessel numbers increased in G-A-50 allantoin compared to other treatment groups, which may be due to the high dose of allantoin. In total, $12.5 \mathrm{mg} / \mathrm{kg}$ allantoin dose presented better results. Initially, we selected 50 and $25 \mathrm{mg}$ doses according to the study of Lee et al. (11). Afterward, because of the positive results obtained, it was decided to use lower doses $(12.5 \mathrm{mg})$. This is an important point in the study showing fewer side effects at lower doses.

One of the prostaglandins in the gastric mucosa is PGE2. PGE2 enhances mucus secretion, inhibits gastric acid secretion, and improves gastric ulcer $(9,13)$. As it has been shown in many studies, our results also indicated that ethanol consumption led to PGE2 
decrease, and allantoin administration in gastritis groups was observed to increase PGE2 levels in the gastric tissue. Previously, it has been documented that allantoin increased the activity of COXs production pathways $(21,23)$. Therefore, it is probable that increased COX1 and COX2 synthesis will cause increased PGE2 secretion in the stomach tissue. It seems that allantoin increases mucosal cells, followed by increased mucus secretion and NP-SH levels. NP-SH compounds and PGE2 help to increase antioxidant defense, to keep on mucus barrier integrity and thereby to improve gastritis.

\section{Conclusions}

This study revealed that allantoin had positive effects on the histopathological indices and could promote and keep the gastric mucosal barrier in ethanol induced gastritis. Moreover, it was found that $12.5 \mathrm{-mg}$ allantoin showed the best results after 5 days of consequent treatment. This caused better results with the lower doses as shown. Therefore, allantoin can help to decrease side effects of the agents and drug interactions.

\section{REFERENCES}

1. Ahn YJ, Park SJ, Woo H, Lee HE, Kim HJ, Kwon G, Gao Q, Jang DS, Ryu JH: Effects of allantoin on cognitive function and hippocampal neurogenesis. Food Chem. Toxicol. 64, 210-216 (2014)

2. Amirshahrokhi K, Khalili AR: Gastroprotective effect of 2-mercaptoethanesulfonate against acute gastric mucosal damage induced by ethanol. Int. Immunopharmacol. 34, 183-188 (2016)

3. Araújo LU, Grabe-Guimarães A, Mosqueira VC, Carneiro CM, Silva-Barcellos NM: Profile of wound healing process induced by allantoin. Acta Cir. Bras. 25(5), 460-466 (2010)

4. Chen MF, Tsai JT, Chen LJ, Wu TP, Yang JJ, Yin LT, Yang YL, Chiang TA, Lu HL, Wu MC: Antihypertensive action of allantoin in animals. Biomed Res. Int. 2014, 690135 (2014)

5. Chung HH, Lee KS, Cheng JT: Decrease of obesity by Allantoin via Imidazoline I1-receptor activation in high fat diet-fed mice. Evid. Based Complement. Alternat. Med. 2013, 589309 (2013)

6. da Rosa RL, de Almeida CL, Somensi LB, Boeing T, Mariano LNB, de Medeiros Amorim Krueger C, de Souza P, Filho VC, da Silva LM, de Andrade SF: Chrysophyllumcainito (apple-star): a fruit with gastroprotective activity in experimental ulcer models. Inflammopharmacology (2017)

7. da Silva DM, Martins JLR, de Oliveira DR, Florentino IF, da Silva DPB, Dos Santos FCA, Costa EA: Effect of allantoin on experimentally induced gastric ulcers: pathways of gastroprotection. Eur. J. Pharmacol. 821, 68-78 (2018)

8. Florentino IF, Silva DPB, Galdino PM, Lino RC, Martins JLR, Silva DM, de Paula JR, Tresvenzol LMF, Costa EA: Antinociceptive and anti-inflammatory effects of Memora nodosa and allantoin in mice. J. Ethnopharmacol. 186, 298-304 (2016)

9. Halim SZ, Zakaria ZA, Omar MH, Mohtarrudin N, Wahab IRA, Abdullah MNH: Synergistic gastroprotective activity of methanolic extract of a mixture of Melastoma malabathricum and Muntingia calabura leaves in rats. BMC Complement. Altern. Med. 17, 488 (2017)

10. Jang S, Bak EJ, Cha JH: N-acetylcysteine prevents the development of gastritis induced by Helicobacter pylori infection. J. Microbiol. 55(5), 396-402 (2017)

11. Lee MY, Lee NH, Jung D, Lee JA, Seo CS, Lee H, Kim JH, Shin HK: Protective effects of allantoin against ovalbumin (OVA)-induced lung inflammation in a murine model of asthma. Int. Immunopharmacol. 10, 474-480 (2010)

12. Li W, Wang X, Zhi W, Zhang H, He Z, Wang Y, Liu F, Niu X, Zhang X: The gastroprotective effect of nobiletin against ethanol-induced acute gastric lesions in mice: impact on oxidative stress and inflammation. Immunopharmacol. Immunotoxicol. 39, 354-363 (2017)

13. Liu W, Shang P, Liu T, Xu H, Ren D, Zhou W, Wen A, Ding Y: Gastroprotective effects of chebulagic acid against ethanol-induced gastric injury in rats. Chem. Biol. Interact. 278, 1-8 (2017) 
14. Madrazo-Jiménez M, Rodríguez-Caballero Á, Serrera-Figallo MÁ, Garrido-Serrano R, Gutiérrez-Corrales A, Gutiérrez-Pérez JL, Torres-Lagares D: The effects of a topical gel containing chitosan, $0,2 \%$ chlorhexidine, allantoin and despanthenol on the wound healing process subsequent to impacted lower third molar extraction. Med. Oral Patol. Oral Cir. Bucal. 21, 696-702 (2016)

15. Moraes TM, Kushima H, Moleiro FC, Santos RC, Rocha LR, Marques MO, Vilegas W, Hiruma-Lima CA: Effects of limonene and essential oil from Citrus aurantium on gastric mucosa: role of prostaglandins and gastric mucus secretion. Chem. Biol. Interact. 180, 499-505 (2009)

16. Moslehi A, Nabavizadeh F, Keshavarz M, Rouhbakhsh N, Sotudeh M, Salimi E, Barzegar Behrooz A: Traffic noise exposure increases gastric pepsin secretion in rat. Acta Med. Iran. 54, 191-195 (2016)

17. Nikoukar LR, Nabavizadeh F, Mohamadi SM, Moslehi A, Hassanzadeh G, Nahrevanian H, Agah S: Protective effect of ghrelin in a rat model of celiac disease. Acta Physiol. Hung. 101, 438-447 (2014)

18. Ozbayer C, Kurt H, Ozdemir Z, Tuncel T, Moheb Saadat S, Burukoglu D, Senturk H, Degirmenci I, Gunes HV: Gastroprotective, cytoprotective and antioxidant effects of Oleum cinnamomi on ethanol induced damage. Cytotechnology 66, 431-441 (2014)

19. Shin JH, Lee CW, Oh SJ, Yun J, Lee K, Park SK, Kim HM, Han SB, Kim Y, Kim HC, Kang JS: Protective effect of silymarin against ethanol-induced gastritis in rats: role of sulfhydryls, nitric oxide and gastric sensory afferents. Food Chem. Toxicol. 55, 353-357 (2013)

20. Song DU, Jang MS, Kim HW, Yoon HJ, Chay KO, Joo YE, Jung YD, Yang SY, Ahn BW: Gastroprotective effects of glutinous rice extract against ethanol, indomethacin, and stress-induced ulcers in rats. Chonnam Med. J. 50, 6-14 (2014)

21. Song JW, Seo CS, Kim TI, Moon OS, Won YS, Son HY, Son JK, Kwon HJ: Protective effects of Manassantin A against ethanol-induced gastric injury in rats. Biol. Pharm. Bull. 39, 221-229 (2016)

22. Yang TT, Chiu NH, Chung HH, Hsu CT, Lee WJ, Cheng JT: Stimulatory effect of allantoin on imidazoline $\mathrm{I}_{1}$ receptors in animal and cell line. Horm. Metab. Res. 44, 879-884 (2012)

23. Yang Y, Yin B, Lv L, Wang Z, He J, Chen Z, Wen X, Zhang Y, Sun W, Li Y, Zhao Y: Gastroprotective effect of aucubin against ethanol-induced gastric mucosal injury in mice. Life Sci. 189, 44-51 (2017) 